\title{
An Empirical Analysis of Perceived Transaction Convenience, Performance Expectancy, Effort Expectancy and Behavior Intention to Mobile Payment of Cambodian Users
}

\author{
Do Nam Hung ${ }^{1}$, Jacquline Tham ${ }^{1}$, S. M. Ferdous Azam ${ }^{1} \&$ Abdol Ali Khatibi ${ }^{1}$ \\ ${ }^{1}$ Faculty of Business Management and Professional Studies, Management and Science University (MSU), \\ Section 13, 40100 Shah Alam, Selangor, Malaysia \\ Correspondence: Do Nam Hung, Management and Science University (MSU), Section 13, 40100 Shah Alam, \\ Selangor, Malaysia. E-mail: hungdn999@gmail.com
}

Received: September 2, 2019 Accepted: September 29, 2019 Online Published: October 16, 2019

doi:10.5539/ijms.v11n4p77 URL: https://doi.org/10.5539/ijms.v11n4p77

\begin{abstract}
Mobile payment (m-payment) is determined as modern application of electronic commerce. It helps financial institutions to widen the financial services to existing customers in developed countries and to increase financial inclusion in developing and emerging countries. Cambodia is a country with low financial inclusion and National Bank of Cambodia perceives that the usage of m-payment can help to increase financial deepness. However, the lack of empirical evidences is a concern and this study is developed to fill the literature gaps. A research model as proposed in which behavior intention towards m-payment is affected by performance expectancy and effort expectancy. This model involves perceived transaction convenience as direct impact on performance expectancy and effort expectancy. Four research hypotheses were proposed and data was collected from 252 questionnaires. Obtained result showed that three hypotheses were supported. Only the effect of perceived transaction convenience on performance expectancy was not significantly. All factors qualified for reliability test's requirement. EFA Analysis was conducted to verify the construct between factors and belonged items. Based on empirical results, recommendations and future researches were proposed.
\end{abstract}

Keywords: Mobile payment (m-payment), perceived transaction convenience, performance expectancy, effort expectancy, behavior intention

\section{Introduction}

Mobile payment (m-payment) refers to the transactions or the payments which are initiated by mobile devices and it receives significant amount of attention (Hayashi, 2012). M-payment was firstly introduced in 1990s and its patent was firstly registered in 2000 (Google Patents, 2019). The first instance of m-payment transaction was initiated by Coca Cola since when the company allowed individual customers to buy the drink through text messages on their mobile phones (Prime Indexes, 2018). Currently, m-payment is conducted under various forms, including mobile wallets, SMS payments, direct operator billing, internet payments, and mobile banking (Prime Indexes, 2018). In 2017, The Statista (2019) emphasizes that the users utilize m-payment mainly for merchandise purchases (US\$168.3 billion), ticketing (US\$6.8 billion), money transfers (US\$497.1 billion), bill payments (US $\$ 36.8$ billion), airtime top-ups (US\$8.5 billion). Asia Pacific is the region with highest number of m-payment users, from 4.9 million people in 2009 to 163.6 million people in 2016 (Prime Indexes, 2018).

M-payment is delivered with two information systems, including short message service (SMS) and near field communication (NFC), according to Liebana-Cabanillas et al. (2017). SMS is defined as the communication between two mobile devices and it consists of short texts (Valcourt et al., 2015). There are some limitations of SMS, including the limited characters per message and there is no delivery confirmation (Kadhiwal \& Zulfiquar, 2007). Recently, NFC is emerged as the replacement of SMS in term of m-payment. NFC is defined as a communication technology which is embedded in the mobile devices of users that enable communication between mobile device and terminal (Liebana-Cabanillas et al., 2017). The benefit of NFC is that it allows the service providers to integrate diversified payment services to the terminal (Grassie, 2007).

The development of m-payments provides the opportunities to financial institutions to provide value added services to existing customers in developed countries and to allow a large number of unbanked customers in 
developing and emerging countries to access formal financial services (Gupta, 2013). Kenya is a practical example of adopting m-payment to expand the formal financial services in poor country. Since m-payment was introduced in the country, the number of m-payment users was increased to more than 8 million and it accounted for $40 \%$ of adult population and later survey showed that Kenyan people have been raising their attention to use m-payment because of this technology becomes familiar with them (Morawczynski \& Pickens, 2009).

Similarly, Cambodia is determined as one of the countries with low financial accessibility to people despite of the financial inclusion index was improved from 6\% in 2008 to $23.5 \%$ in 2014 (Sarma, 2016). Regarding to such situation, m-payment is considered as the solution to further improve financial inclusion in the country (Seng \& Lay, 2018). It is supported by the fact that the number of mobile cellular subscribers per population in Cambodia has reached $134 \%$ recently (Sarma, 2016) in which $13.27 \%$ of mobile phone users have been using smartphones (Finmark Trust, 2015). It is concluded that financial inclusion deepness is achievable through the application of advanced technologies, especially mobile phones (Seng \& Lay, 2018). The role of m-payment is recognized throughout its indirect effect to economic growth. This indirect effect is further explained by the fact that m-payment helps the countries to increase financial inclusion and higher financial inclusion returns significant and positive effect to economic growth (Levine et al., 2000; Claessens, 2006; Demirguc-Kunt et al., 2015).

The study aims to explore how the behavior intention of Cambodian users towards m-payment. This research aim is motivated by the lack of empirical studies about behavior intention in the relationship with performance expectancy, effort expectancy, and perceived transaction convenience. Previous researchers like Seng and Lay (2018) studied about m-payment and how it can induce the people to formal financial services. Hoffman and McVay (2013) developed a report about m-payment service provider in Cambodia but the main content was about business and operation strategies of this company.

\section{Literature Survey}

There are many theories which were developed by previous researchers to explore how individual interacts and adopt with new technologies. The existing theories refer to Theory of Reasoned Action developed by Ajzen and Fishbein (1980), Theory of Planned Behavior developed by Ajzen (1991). Both these theories explore how users develop their understanding and are able to use information system. The theoretical basis of Theory of Reasoned Action and Theory of Planned Behavior is users' attitudes and subjective norms related to the users (Yang et al., 2012). Another theoretical model was developed by Davis (1989) under the name of Technology Acceptance Model. This model involved perceived usefulness and perceived ease of use as determinants of intention to use new technology (Davis et al., 1989). Many researchers adopted Theory of Reasoned Action, Theory of Planned Behavior, and Technology Acceptance Model to explain how the users' intention towards mobile phone usage (Ervasti \& Helaakoski, 2010), healthcare system (Pai \& Huang, 2011), social network (Lorenzo et al., 2011). Some researchers were relied on Technology Acceptance Model to explain users' intention to m-payment system (Liebana-Cabanillas, 2012; Luna, 2012). Recently, Unified Theory of Acceptance and Use of Technology model which was developed by Venkatesh et al. (2003) was proven as playing an important role in technology acceptance research (De Wit et al., 2011; Verhoeven et al., 2011). A comparison between Theory of Reasoned Action, Theory of Planned Behavior, Technology Acceptance Model, and Unified Theory of Acceptance and Use of Technology model was provided by Samaradiwakara and Gunawardena (2014) and it showed that the last model has highest variance explain. In more detail, variance explained in Theory of Reasoned Action, Theory of Planned Behavior, and Technology Acceptance Model was 0.36, 0.53, and 0.46. Other while, Unified Theory of Acceptance and Use of Technology model achieved variance explain of 0.69 .

\section{Research Model and Hypothesis}

The research model is depicted in Figure 1:

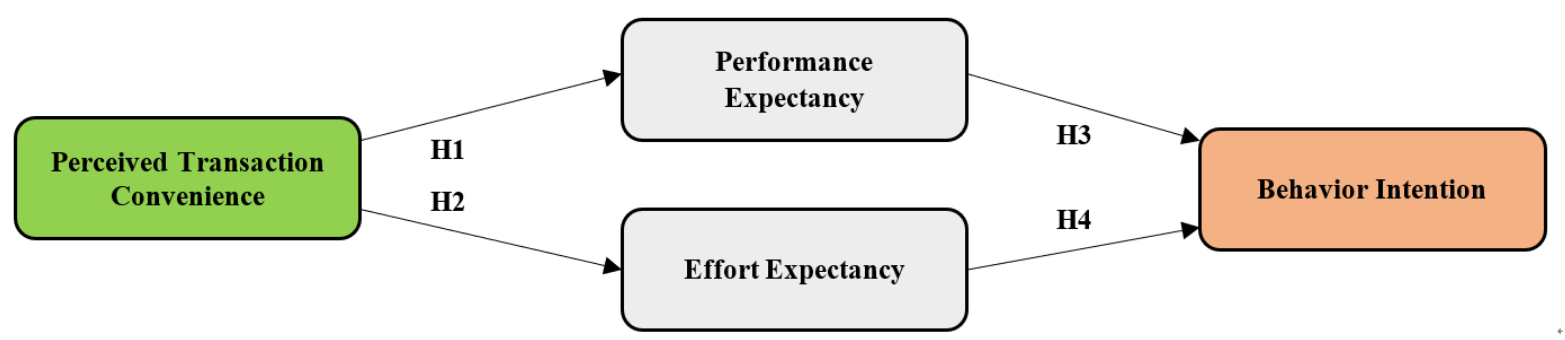

Figure 1. Research model 
Thus, there are four research hypotheses:

Perceived transaction convenience is defined as the ease of making and amend transactions by the users (Beauchamp \& Ponder, 2010). The role of perceived transaction convenience was proven in online shopping whether easy and safe payment method is crucial to the users (Ferreira, 2016). Empirical evidence provided by Javadi et al. (2012) confirmed that when users perceived high possibility of money lost, their behavior intention was affected negatively. Shaw and Sergueeva (2016) identified that perceived transaction convenience affects significantly and positively on user intention to use smartphone for mobile commerce. Liebana-Cabanillas et al. (2017) considered perceived transaction convenience as perceived security and it affected significantly intention to use new m-payment among 287 respondents. Teo et al. (2015) obtained empirical evidence of perceived transaction convenience affected to both performance expectancy and effort expectancy. Umphapalin (2018) developed research about factors affecting behavior intention to use quick response payment system of consumer of Bangkok, Thailand and this researcher confirmed that performance expectancy and effort expectancy were significantly affected by performance transaction convenience. Therefore, the first two hypotheses are:

H1: Perceived transaction convenience has significant effect to performance expectancy.

$\mathrm{H} 2$ : Perceived transaction convenience has significant effect to effort expectancy.

Performance expectancy is defined as the users' expectation to the performance of adopted technology (Sarfaraz, 2017). The effect of performance expectancy on behavior intention is found as significant in previous empirical evidences. Jambulingam (2013) adopted UTAUT model to study behavior intention to adopt mobile technology and this researcher identified that the hypothesis of performance expectancy has a positive influence on behavioral intention is supported. Ghalandari (2012) conducted a survey among 310 e-banking users in Iran and identified that performance expectancy has significant effect on users' behavior intention. Ayoade (2015) developed a research paper of factors influencing users' behavior intention towards mobile learning technology and performance expectancy has greatest effect on behavior intention compared to effort expectancy, social influence, and facilitating condition. Ali Sair and Danish (2018) confirmed the effect of performance expectancy on behavior intention towards mobile commerce in Pakistan. Therefore, the third hypothesis is:

H3: Performance expectancy has significant effect to behavior intention.

Effort expectancy is defined as user perception of how they can use a technology easily (Onaolapo \& Oyewole, 2018). The effect of effort expectancy on behavior intention is found as significant in previous empirical evidences. An et al. (2016) found significant effect of effort expectancy on online shopping intention among 387 users. Catherine et al. (2017) studied behavior intention towards fingerprint authentication-based ATMs in Uganda and they confirmed that behavior intention was received significant and positive effect from effort expectancy. Mtebe and Raisamo (2014) highlighted the significant effect of effort expectancy on behavior intention of students towards mobile learning in higher education in East Africa. Similarly, Fadzil (2018) confirmed the role of effort expectancy to behavior intention to use mobile applications in Malaysia. Therefore, the fourth hypothesis is:

H4: Effort expectancy has significant effect to behavior intention.

\section{Research Methodology}

Deductive approach is applied in this study since research model is supported by empirical evidences from other researchers. Exploratory research design is chosen since this study focuses on hypothesis testing and identification of relationships between variables. Moreover, quantitative method is chosen in order to reveal the impacts of perceived transaction convenience to performance expectancy and effort expectancy as well as the impact from these two expectancy factors to behavior intention. The application of this research method requires the collection of numerical data from structured questionnaire. In more detail, each factor is measured through multiple items. A total of 32 items are prepared and listed in Figure 2. Each item is evaluated by the respondents and the evaluation is supported by a Likert scale. Primarily, the respondents' attitudes are mainly characterized into "agree", "neutral", and "disagree" attitude. To further rank the attitude, "strong agree" and "strongly disagree" are added into the survey scale. The score of 1 and 2 represents for "strongly disagree" and "disagree". The score of 3 represents for "no idea" and the score of 4 and 5 represents for "agree" and "strongly agree". In addition, the questionnaire includes some questions to collect the usage of Cambodian users towards m-payment as well as their demographic characteristics.

After the questionnaire is prepared, it is delivered to the respondents. The delivery mode is by hand. A total of 252 questionnaires are collected back and they qualify the requirements in which all questionnaires are filled up with the answers or there no null value represented in collected data. The data, then, is inputted to Excel file 
before it is imported to SPSS and AMOS software in order to run some statistical analyses. Frequency analysis, reliability test and exploratory factor analysis are run by SPSS software. Structural Equation Modeling (SEM) technique is used to verify hypotheses and it is run by AMOS software.

\section{Empirical Analysis}

Empirical analysis covers the exploration of characteristics of the respondents. Reliability test and exploratory factor analysis (EFA) are utilized in order to check the internal consistency and the construct of research model. Both reliability test and EFA are run through SPSS software. Lastly, the research utilizes AMOS software to validate hypotheses.

\subsection{The Characteristics of the Respondents}

The characteristics of the respondents is firstly explored through how they are using m-payment:
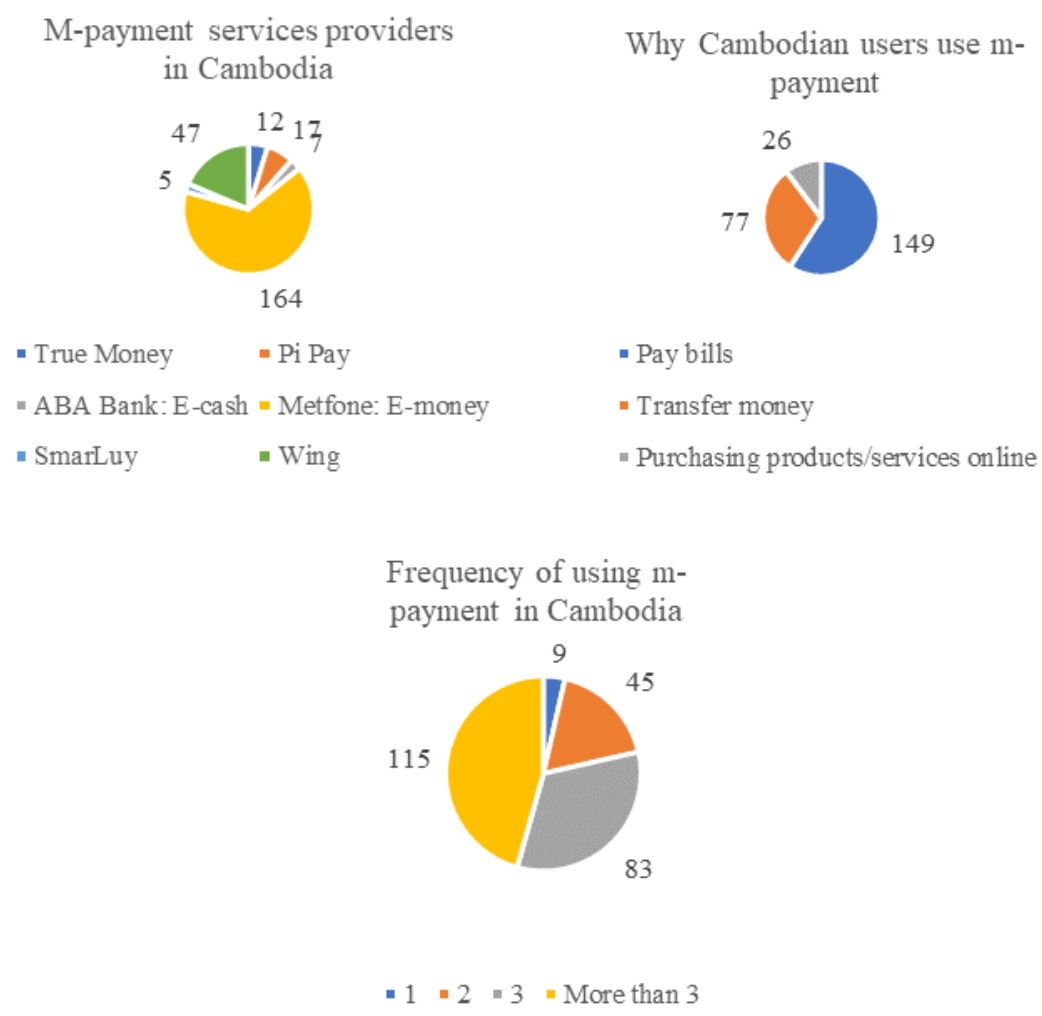

Figure 2. How Cambodian users to use m-payment

Figure 3 shows that Metfone: E-money is being used intensively by the respondents since 164 respondents $(65.1 \%)$ is using m-payment service from this provider. The second provider is Wing with 47 respondents $(18.7 \%)$. Other m-payment services providers take small portion in the sample. Then, the purpose of using $\mathrm{m}$-payment is clarified in which, 149 respondents use m-payment to pay bills, 77 respondents use m-payment to transfer money, and only 26 respondents use m-payment for online purchasing. Lastly, the frequency of using m-payment is explored. It is divided into 1 time, 2 times, 3 times, and more than 3 times. Only 9 respondents use m-payment for 1 time, 45 respondents use m-payment for 2 times, and 198 respondents have at least 3 times of using m-payment.

In addition, gender, age, education, marital status, monthly income, and occupation of the respondents are explored: 
Gender

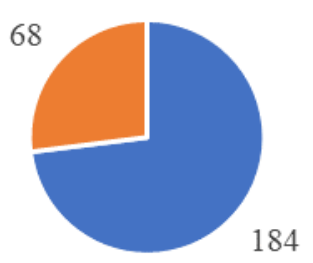

- Male - Famale
Age

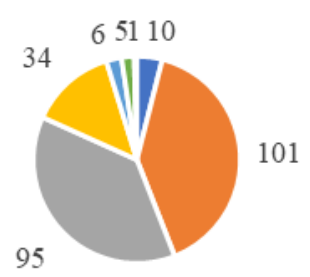

- Less than $20 \quad$ - 21-25

$=26-30$

- $36-40$

$=31-35$

- $41-45$

\section{Education}

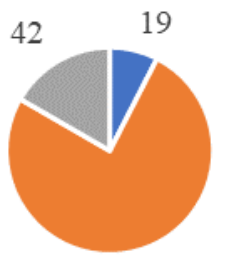

191

- High school and below

- Bachelor

Master

Marital status

Income
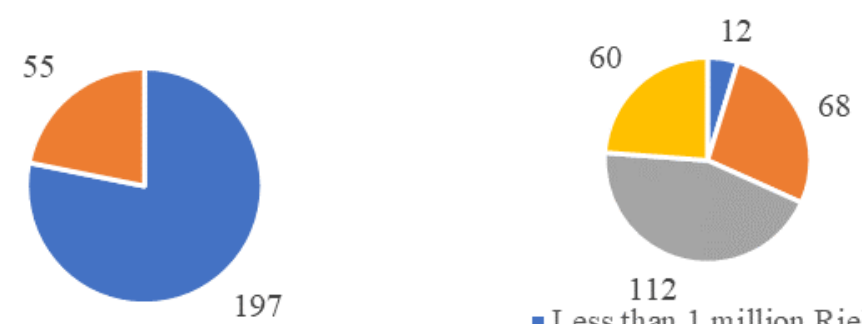

112

- Less than 1 million Riel

- 1-3 million Riel

- 3-5 million Riel

- Single - Married

\section{Occupation}

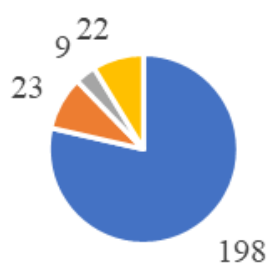

$$
\begin{aligned}
& \text { - Professional } \text { - Management } \\
& \text { - Student }
\end{aligned}
$$

Figure 3. The demographic characteristics of Cambodian users

It is captured that male respondents are much higher than female respondents in the sample. There are 184 males and 68 females. The respondents' age is quite young since 206 people with age less than 30 years old. There are 
34 respondents age between 31 and 35 and only 12 respondents more than 35 years old in the sample. Education of the respondents is divided into high school and below (19 people), bachelor (191 people), and master (42 people). Among 252 respondents, only 55 people are married and 197 people are single. Monthly income of the respondents is divided into less than 1 million Riel, 1-3 million Riel, 3-5 million Riel, and more than 5 million Riel. Only 12 people is categorized in less than 1 million Riel, 68 people within 1-3 million Riel income group, 112 people with monthly income from 3 to 5 million Riel, and 60 people earn more than 5 million Riel per month. Finally, occupation of the respondents is explored and obtained result shows that 198 respondents are professional, 23 people has management occupation, 22 self-employees, and 9 students. Based on the descriptive statistics, there are some conclusions about the respondents. At first, m-payment service is attractive to males rather than females. Cambodian users who use m-payment services are young and they also have good education level. Moreover, m-payment users are single and they earn below average income although most of the respondents are professionals.

\subsection{Descriptive Statistics}

Descriptive statistics refer to the calculation of mean value. The result is presented in Table 1:

Table 1. Descriptive statistics

\begin{tabular}{|c|c|c|c|c|c|c|c|}
\hline \multicolumn{2}{|c|}{ Performance expectancy } & \multicolumn{2}{|c|}{ Effort expectancy } & \multicolumn{2}{|c|}{ Perceived transaction convenience } & \multicolumn{2}{|c|}{ Behavior intention } \\
\hline Item & Mean & Item & Mean & Item & Mean & Item & Mean \\
\hline PE1 & 3.008 & EE1 & 3.337 & PTC1 & 3.667 & BI1 & 2.647 \\
\hline PE2 & 3.230 & EE2 & 3.111 & PTC2 & 3.817 & $\mathrm{BI} 2$ & 2.647 \\
\hline PE3 & 3.115 & EE3 & 3.131 & PTC3 & 3.552 & $\mathrm{BI} 3$ & 2.619 \\
\hline PE4 & 2.952 & EE4 & 3.337 & PTC4 & 3.952 & $\mathrm{BI} 4$ & 2.575 \\
\hline PE5 & 3.460 & EE5 & 3.448 & PTC5 & 3.560 & BI5 & 2.647 \\
\hline PE6 & 2.913 & EE6 & 3.587 & PTC6 & 4.238 & BI6 & 2.591 \\
\hline PE7 & 3.143 & EE7 & 3.377 & PTC7 & 3.405 & BI7 & 2.627 \\
\hline PE8 & 3.143 & & & & & BI8 & 2.567 \\
\hline PE9 & 3.115 & & & & & BI9 & 2.560 \\
\hline
\end{tabular}

Performance expectancy has no items with mean value more than 3.5 or less than 2.5. In other words, all items of performance expectancy have mean values between 2.5 and 3.5 in which mean values of PE1 to PE9 are $3.008,3.230,3.115,2.952,3.460,2.913,3.143,3.143$, and 3.115. Highest and lowest mean value is belonged to PE5 and PE6. It is also concluded that the respondents provide neutral attitude towards each statement of performance expectancy.

Effort expectancy has one item with mean value more than $3.5(E E 5$ 's mean value $=3.587)$ and other items have mean values between 2.5 and 3.5. Mean values of EE1 to EE7 are 3.337, 3.111, 3.131, 3.337, 3.448, 3.587, and 3.377. The respondents agree that m-payment is easy to interact with and they provide neutral attitude towards other aspects of effort expectancy.

Perceived transaction convenience has only one item with mean value less than 3.5 (PTC7's mean value $=3.405$ ) while other items have mean values more than 3.5. Mean values of PTC1 to PTC7 are 3.667, 3.817, 3.552, 3.952, $3.560,4.238$, and 3.405. The respondents, therefore agree with all statements of perceived transaction convenience. Highest mean value is belonged to PTC6 (mean value $=4.238$ ).

Behavior intention has no items with mean value more than 3.5 or less than 2.5. All items of this factor have mean values between 2.5 and 3.5 in which mean values of BI1 to BI9 are 2.647, 2.647, 2.619, 2.575, 2.647, $2.591,2.627,2.567$, and 2.560 . It is also concluded that the respondents provide neutral attitude towards each statement of performance expectancy. The items of behavior intention have mean values much lower than the items of performance expectancy, effort expectancy, and perceived transaction convenience.

\subsection{Reliability Analysis}

Reliability test analysis is used to check the internal consistency between items. This analysis is run for each factor and its belonged items. There are two requirements related to the test. At first, each item must be correlated significantly with each other and it is measured through corrected item-total correlation which is calculated for each item. The minimum value of corrected item-total correlation is 0.30 . The second requirement addresses that the construct between items must be stable or when deleting one item, overall reliability of the factor should be improved. It is quantified by using Cronbach's alpha value after an item is deleted. Overall 
reliability level of a factor is measured by Cronbach's alpha and the higher value of Cronbach's alpha means the higher internal consistency between items.

However, acceptable range of Cronbach's alpha is between 0.7 and 0.9 (Pallant, 2013). Any value less than 0.7 is not acceptable while too high Cronbach's alpha (i.e., more than 0.9) poses a concern of the scale (Ursachi et al., 2015).

Table 2. Reliability test analysis

\begin{tabular}{|c|c|c|c|c|c|c|c|c|c|c|c|}
\hline \multicolumn{3}{|c|}{ Performance expectancy } & \multicolumn{3}{|c|}{ Effort expectancy } & \multicolumn{3}{|c|}{$\begin{array}{l}\text { Perceived transaction } \\
\text { convenience }\end{array}$} & \multicolumn{3}{|c|}{ Performance expectancy } \\
\hline $\begin{array}{l}\text { Cronbach's } \\
\text { alpha }\end{array}$ & 0.899 & & $\begin{array}{l}\text { Cronbach's } \\
\text { alpha }\end{array}$ & 0.883 & & $\begin{array}{l}\text { Cronbach's } \\
\text { alpha }\end{array}$ & 0.839 & & $\begin{array}{l}\text { Cronbach's } \\
\text { alpha }\end{array}$ & 0.899 & \\
\hline Item & Rq.1 & $\mathrm{Rq} 2$ & Item & Rq.1 & $\mathrm{Rq} 2$ & Item & Rq.1 & $\mathrm{Rq} 2$ & Item & Rq.1 & $\mathrm{Rq} 2$ \\
\hline PE1 & 0.728 & 0.882 & EE1 & 0.704 & 0.862 & PTC1 & 0.555 & 0.823 & BI1 & 0.701 & 0.886 \\
\hline PE2 & 0.699 & 0.885 & EE2 & 0.580 & 0.877 & PTC2 & 0.682 & 0.807 & $\mathrm{BI} 2$ & 0.606 & 0.893 \\
\hline PE3 & 0.555 & 0.896 & EE3 & 0.638 & 0.871 & PTC3 & 0.613 & 0.815 & $\mathrm{BI} 3$ & 0.604 & 0.893 \\
\hline PE4 & 0.738 & 0.881 & EE4 & 0.757 & 0.855 & PTC4 & 0.585 & 0.818 & $\mathrm{BI} 4$ & 0.753 & 0.882 \\
\hline PE5 & 0.804 & 0.877 & EE5 & 0.675 & 0.866 & PTC5 & 0.593 & 0.819 & BI5 & 0.722 & 0.884 \\
\hline PE6 & 0.544 & 0.898 & EE6 & 0.639 & 0.870 & PTC6 & 0.686 & 0.803 & BI6 & 0.633 & 0.891 \\
\hline PE7 & 0.749 & 0.883 & EE7 & 0.731 & 0.858 & PTC7 & 0.497 & 0.836 & BI7 & 0.750 & 0.882 \\
\hline PE8 & 0.678 & 0.887 & & & & & & & BI8 & 0.609 & 0.892 \\
\hline PE9 & 0.539 & 0.897 & & & & & & & BI9 & 0.652 & 0.889 \\
\hline
\end{tabular}

Cronbach's alpha of performance expectancy is 0.899 . Corrected item-total correlation values of all items belonged to this factor are higher than 0.30 (Rq.1). When deleting each item subsequently, new Cronbach's alpha (Rq.2) is all less than 0.899. Similarly, Cronbach's alpha value of performance expectancy is calculated at 0.883 . Both Rq. 1 and Rq. 2 are satisfied the conditions of none items have corrected item-total correlation less than 0.3 and new Cronbach's alpha is less than 0.883 . Perceived transaction convenience and behavior intention have Cronbach's alpha higher than 0.8 and less than 0.90 . These factors also pass two requirements of reliability test. It is concluded that all 32 items are kept after reliability test and they are able to subject to EFA analysis.

\subsection{EFA Analysis}

EFA analysis is generally used to verify the construct between items. The application of EFA allows the researcher to validate proposed research model. Before running EFA, KMO and Bartlett's test for Sphericity must be validated. The minimum value of KMO is 0.5 while Bartlett's test must be statistically significant at $95 \%$ confidence level. These requirements are passed since KMO value is calculated at 0.840 and $\mathrm{p}$-value of Bartlett's test is less than 0.0001 or $99.99 \%$ confidence level.

The next step of EFA is to identify significant component which is defined as the components with initial eigenvalues more than 1.0. It is denoted that total number of components is equal to total number of items in the questionnaire. Herein, there are 32 components to be extracted but only the first four components are selected. Initial eigenvalues of Component 1, Component 2, Component 3, and Component 4 are 7.070, 4.481, 3.604, and 3.258. From Component 5 to Component 32, initial eigenvalues are less than 1.0 so that they are not selected. Furthermore, selected components can explain well for the data variance since they are able to explain for $57.542 \%$ of total variance.

Detail of EFA analysis is presented in Table 3: 
Table 1. EFA analysis result after Varimax rotation

\begin{tabular}{|c|c|c|c|c|}
\hline \multicolumn{5}{|c|}{$\mathrm{KMO}=0.840 ;$ Bartlett's test $=4471.696 ;$ P-value $<0.0001$} \\
\hline \multirow[t]{2}{*}{ Items } & \multicolumn{4}{|c|}{ Component } \\
\hline & 1 & 2 & 3 & 4 \\
\hline $\mathrm{BI} 7$ & 0.811 & & & \\
\hline BI4 & 0.805 & & & \\
\hline BI1 & 0.779 & & & \\
\hline BI5 & 0.773 & & & \\
\hline $\mathrm{BI} 2$ & 0.715 & & & \\
\hline BI9 & 0.701 & & & \\
\hline BI6 & 0.693 & & & \\
\hline $\mathrm{BI} 8$ & 0.679 & & & \\
\hline $\mathrm{BI} 3$ & 0.666 & & & \\
\hline PE5 & & 0.868 & & \\
\hline PE7 & & 0.816 & & \\
\hline PE4 & & 0.801 & & \\
\hline PE1 & & 0.767 & & \\
\hline PE2 & & 0.755 & & \\
\hline PE8 & & 0.752 & & \\
\hline PE3 & & 0.653 & & \\
\hline PE9 & & 0.649 & & \\
\hline PE6 & & 0.586 & & \\
\hline EE4 & & & 0.811 & \\
\hline EE7 & & & 0.806 & \\
\hline EE1 & & & 0.791 & \\
\hline EE6 & & & 0.785 & \\
\hline EE5 & & & 0.738 & \\
\hline EE3 & & & 0.696 & \\
\hline EE2 & & & 0.680 & \\
\hline PTC6 & & & & 0.798 \\
\hline PTC2 & & & & 0.785 \\
\hline PTC5 & & & & 0.722 \\
\hline PTC3 & & & & 0.704 \\
\hline PTC1 & & & & 0.694 \\
\hline PTC4 & & & & 0.694 \\
\hline PTC7 & & & & 0.626 \\
\hline Factor loading & 7.070 & 4.481 & 3.604 & 3.258 \\
\hline$\%$ of Variance & 22.094 & 14.003 & 11.263 & 10.182 \\
\hline Cumulative $\%$ & 22.094 & 36.097 & 47.359 & 57.542 \\
\hline
\end{tabular}

Through the EFA result, the researcher perceives that proposed research model is good since the construct between items of one factor remains strongly. Component 1,2, 3, and 4 represent for behavior intention, performance expectancy, effort expectancy, and perceived transaction convenience. Factor loading values of the items are all higher than 0.5. In Component 1, highest factor loading value is belonged to BI7 while lowest factor loading value is belonged to BI3. In Component 2, highest factor loading value and lowest factor loading value are belonged to PE5 and PE6 respectively. In Component 3, EE4 has highest factor loading value and EE2 has lowest factor loading value. Finally, PTC6 and PTC7 are two items of perceived transaction convenience factor and they have highest and lowest factor loading values compared to other items. 


\subsection{Analysis}

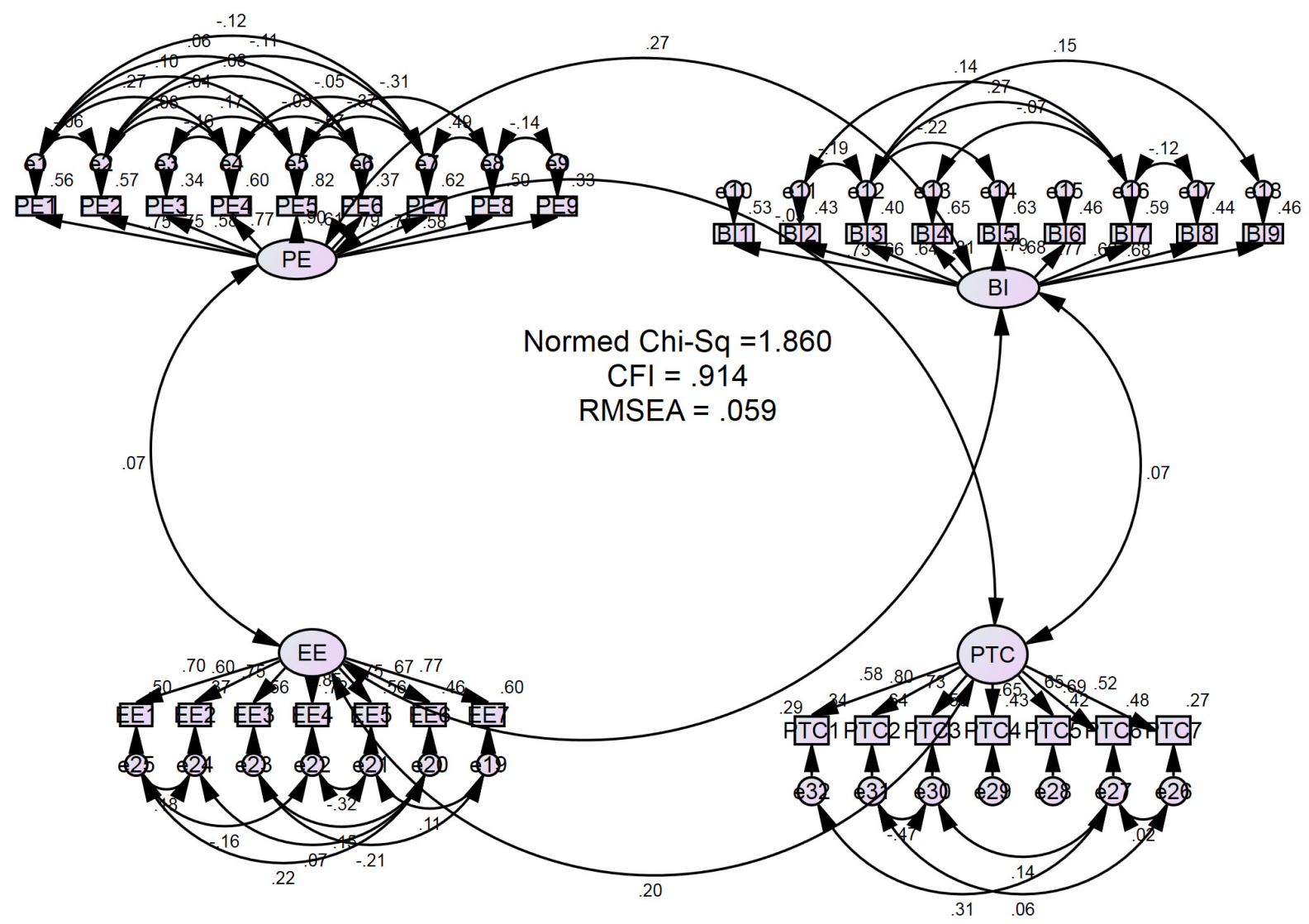

Figure 4. Confirmatory factor analysis (CFA) of overall measurement model

Table 4. CFA results for overall measurement model

\begin{tabular}{lllll}
\hline Goodness of fit statistics & Initial Model & Modified Model & Threshold value for the fit indices & Results \\
\hline Normed Chi-Square & 1.860 & No Modification & $<5.0$ & Qualify the benchmark \\
CFI & 0.914 & No Modification & $>0.9$ & Qualify the benchmark \\
RMSEA & 0.059 & No Modification & $<0.08$ & Qualify the benchmark \\
\hline
\end{tabular}

To evaluate research model, AMOS is utilized and the output of model fit is presented in Table 4 above

It is denoted that Chi-square/df (CMIN/DF) is 1.860 and it is lower than 5. CFI value is calculated at 0.914 which is slightly more than 0.9 and RMSEA is 0.059 which is less than 0.08 . According to the results, Normed Chi-Square, CFI and RMSEA qualify the benchmark and suggest a good fit. It is concluded the model is perfectly fit with the dataset. In the next section, the researcher goes to Structural Model Analysis 


\subsection{SEM Analysis}

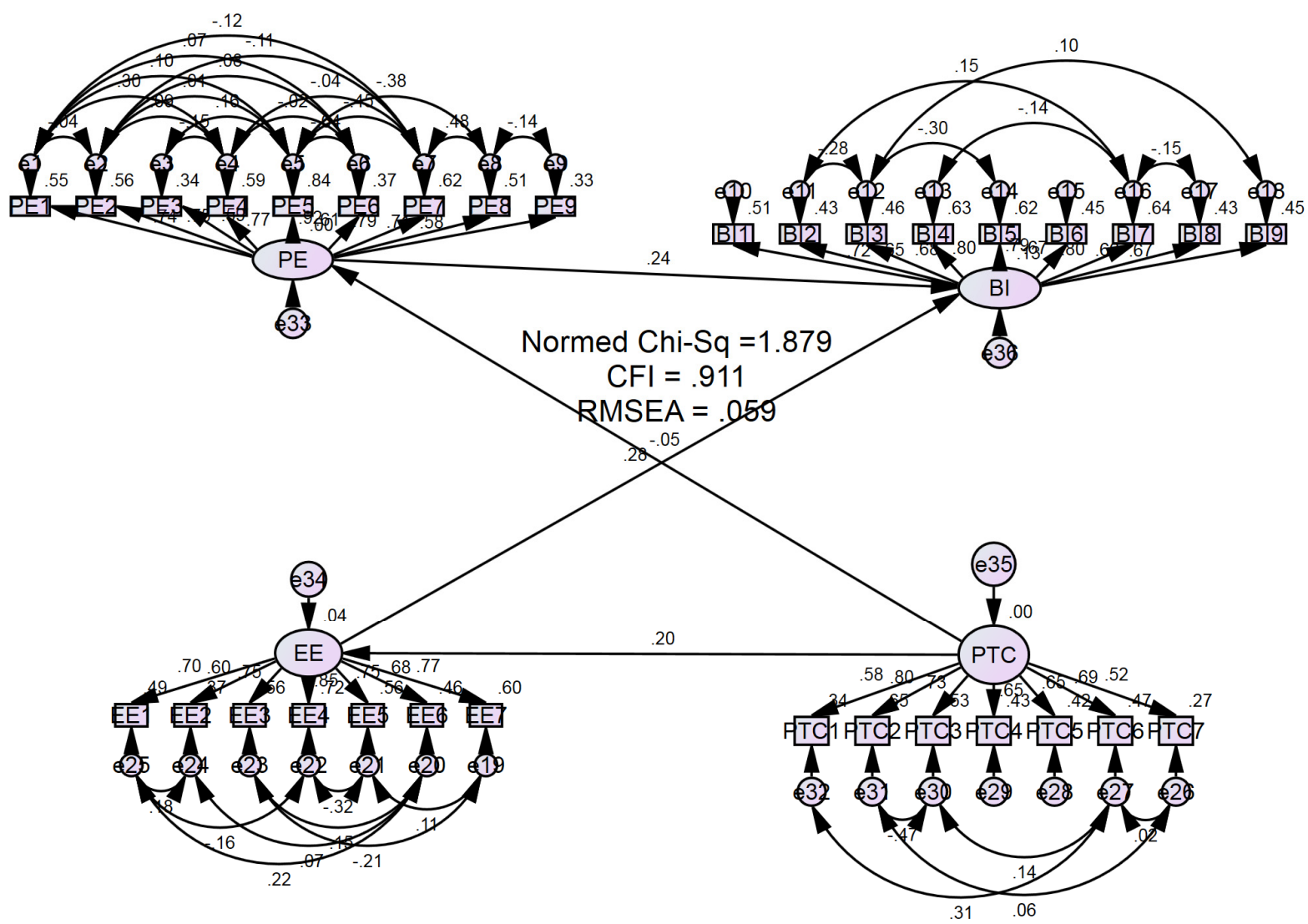

Figure 5. Confirmatory factor analysis (CFA) of overall structural model

Table 5. CFA results for overall structural model

\begin{tabular}{lllll}
\hline Goodness of fit statistics & Initial Model & Modified Model & Threshold value for the fit indices & Results \\
\hline Normed Chi-Square & 1.879 & No Modification & $<5.0$ & Qualify the benchmark \\
CFI & 0.911 & No Modification & $>0.9$ & Qualify the benchmark \\
RMSEA & 0.059 & No Modification & $<0.08$ & Qualify the benchmark \\
\hline
\end{tabular}

It is denoted that Chi-square/df (CMIN/DF) is 1.879 and it is lower than 5. CFI value is calculated at 0.911 which is slightly more than 0.9 and RMSEA is 0.059 which is less than 0.08 . According to the results, Normed Chi-Square, CFI and RMSEA qualify the benchmark and suggest a good fit. It is concluded the model is perfectly fit with the dataset.

\subsection{Hypothesis Testing}

The next step is to verify four hypotheses. Obtained result is presented in Table 6:

Table 6. Hypothesis testing

\begin{tabular}{|c|c|c|c|c|c|c|c|}
\hline Effect & & & Estimate & S.E. & C.R. & $\mathbf{P}$ & Results \\
\hline H1 Performance Expectancy & $<--$ & Perceived Transaction Convenience & -0.08 & 0.108 & -0.742 & 0.458 & Rejected \\
\hline H2 Effort Expectancy & $<--$ & Perceived Transaction Convenience & 0.287 & 0.106 & 2.722 & 0.006 & Accepted \\
\hline H3 Behavior Intention & $<---$ & Effort Expectancy & 0.238 & 0.058 & 4.089 & $* * *$ & Accepted \\
\hline H4 Behavior Intention & $<---$ & Performance Expectancy & 0.182 & 0.051 & 3.579 & $* * *$ & Accepted \\
\hline
\end{tabular}

Hypothesis 1: Perceived Transaction Convenience has significant effect to Performance Expectancy.

The first hypothesis addresses that perceived transaction convenience doesn't have significant effect to 
performance expectancy. Estimated coefficient for this effect is -0.80 and p-value is 0.458 . Since p-value is much higher than 0.05 , null hypothesis is not rejected or perceived transaction convenience has no significant effect to performance expectancy among Cambodian users towards m-payment.

Hypothesis 2: Perceived transaction convenience has significant effect to effort expectancy.

The second hypothesis addresses that perceived transaction convenience has significant effect to effort expectancy. Estimated coefficient for this effect is 0.287 and p-value is 0.006 . Since p-value is less than 0.05 , null hypothesis is rejected or perceived transaction convenience has significant effect to effort expectancy among Cambodian users towards m-payment.

Hypothesis 3: Performance expectancy has significant effect to behavior intention.

The third hypothesis addresses that performance expectancy has significant effect to behavior intention. Estimated coefficient for this effect is 0.182 and p-value is less than 0.05 . Thus, null hypothesis is rejected or performance expectancy has significant effect to behavior intention among Cambodian users towards m-payment.

Hypothesis 4: Effort expectancy has significant effect to behavior intention.

The last hypothesis addresses that effort expectancy has significant effect to behavior intention. Estimated coefficient for this effect is 0.238 and p-value is less than 0.05 . Thus, null hypothesis is rejected or effort expectancy has significant effect to behavior intention among Cambodian users towards m-payment.

\section{Discussion of Empirical Results}

This research paper explores the characteristics of m-payment users in Cambodia and it was found that mobile payment service is attractive to males rather than females. Cambodian users who use mobile payment services are young and they also have good education level. Moreover, mobile payment users are single and they earn below average income although most of the respondents are professionals. All factors qualified reliability test. Cronbach's alpha of perceived transaction convenience, performance expectancy, effort expectancy, and behavior intention were $0.839,0.889,0.883$, and 0.899 . EFA analysis confirmed the research model. Empirical result for proposed model confirmed the significant effect of perceived transaction convenience on effort expectancy. This finding was aligned with empirical evidences provided by Teo et al. (2015) and Umphapalin (2018). However, the effect of perceived transaction convenience on performance expectancy was not supported. It can be explained by the lack of knowledge about m-payment and its benefits among Cambodian users. Furthermore, it was identified that behavior intention towards m-payment of Cambodian users is affected significantly by performance expectancy and the same result was found in the studies of Ghalandari (2012), Ayoade (2015), and Ali Sair and Danish (2018). The effect of effort expectancy on behavior intention towards m-payment was significant and this result was supported by An et al. (2016), Catherine et al. (2017), Fadzil (2018). In addition, SEM analysis showed that EE1 to EE5 was affected significantly by effort expectancy as latent variable in which EE4 received highest effect. Similarly, all items of effort expectancy, perceived transaction convenience, and behavior intention were also affected by the latent variables.

\section{Conclusion and Future Researches}

This research paper was developed with the objective of quantifying the effect of performance expectancy and effort expectancy on behavior intention. This paper also examined how perceived transaction convenient affects performance expectancy and effort expectancy. Obtained result was promised since behavior intention towards m-payment services in Cambodia is well-explained by users' perception towards performance expectancy and effort expectancy. However, perceived transaction convenience is only significant in the relationship with effort expectancy. Other while, performance expectancy is not affected significantly by perceived transaction convenience. Based on the findings, it is recommended that Cambodian governments should further improve m-payment services through national communication campaign to raise the awareness of local users about the benefits of m-payment. It also helps the country to increase financial inclusion and therefore obtaining higher economic growth. The communication message should be straightforward to the transaction ease and safety so that the users are encouraged to use m-payment and they are not worry of losing money or financial details. M-payment services providers in Cambodia should review their security system to ensure that all cyberattacks to $\mathrm{m}$-payment system are monitored strictly. The providers should perform promotion campaigns in order to attract more people to use m-payment services. The promotion campaign refers to the point accumulation and point transformation to free gifts. Different products and services must be developed to meet different demands from the customers such as bill pay, online purchase, etc.

There are some limitations to be found in this research paper. First, empirical result was found on small sample 
of Cambodian users. It was recapped that there are 252 successful questionnaires which were used in this study. Second, the choice of questionnaire as data collection method posed the concern of data quality since obtained information was much depended on the knowledge of the respondents or the respondents' attitudes. In fact, some respondents were very busy and they might answer the questionnaires without thinking, leading to the obtained information did not reflect the fact. However, developed research model was fit well with the data. Normed Chi-Squared, CFI and RMSEA value qualified the requirement of best fitted model. Therefore, future researchers should employ higher number of respondents to the sample and study more variable whether they affect the behavior intention to use mobile payment in Cambodia. They should validate the measurement items and the construct between factors in order to find underlying relationship between items. In-depth interviews should be developed to highlight the issues which cannot be revealed by quantitative data analysis.

\section{References}

Ajzen, I. (1991). Theory of planned behavior. Organizational Behavior and Human Decision Processes, 50(2), 179-211. https://doi.org/10.1016/0749-5978(91)90020-T

Ajzen, I., \& Fishbein, M. (1980). Understanding attitudes and predicting social behavior. Prentice-Hall, Englewood Cliffs.

Ali, S. S., \& Danish, R. Q. (2018). Effect of Performance Expectancy and Effort Expectancy on the Mobile Commerce Adoption Intention through Personal Innovativeness among Pakistani Consumers. Pakistan Journal of Commerce and Social Sciences, 12(2), 501-520.

An, L., Han, Y., \& Tong, L. (2016). Study on the factors of online shopping intention for fresh agricultural products based on UTAUT2. 2nd Information Technology and Mechatronics Engineering Conference (ITOEC 2016). https://doi.org/10.2991/itoec-16.2016.57

Ayoade, O. B. (2015). Factors influencing students' behavioural intention to adopt and use mobile learning in higher educational institutions in Nigeria: An example of Ekiti State University, Ado-Ekiti. International Journal of Emerging Technology and Advanced Engineering, 5(4), 307-313.

Catherine, D., Geofrey, K. M., Moya, M. B., \& Aballo, G. (2017). Effort expectancy, performance expectancy, social influence and facilitating conditions as predictors of behavioural intentions to use ATMS with fingerprint authentication in Ugandan banks. Global Journal of Computer Science and Technology: E Network, Web \& Security, 17(5), 5-22.

Claessens, S. (2006). Access to financial services: A review of the issues and public policy objectives. World Bank Research Observer, 21(2), 207-240. https://doi.org/10.1093/wbro/lk1004

Davis, F. D., Bagozzi, R. P., \& Warshaw, P. R. (1989). User acceptance of computer technology: A comparison of two theoretical models. Management Science, 35(8), 982-1003. https://doi.org/10.1287/mnsc.35.8.982

De Wit, K., Heerwegh, D., \& Verhoeven, J. C. (2011). Changes in the basic ICT skills of freshmen between 2005 and 2009: who's catching up and who's still behind? Education \& Information Technologies. https://doi.org/10.1007/s10639-011-9154-z

Demirguc-Kunt, A., Klapper, L., Singer, D., \& van Oudheusden, P. (2015). The global Findex database 2014: Measuring financial inclusion around the world. Policy Research Working Paper Series 7255. The World Bank. https://doi.org/10.1596/1813-9450-7255

Ervasti, M., \& Helaakoski, H. (2010). Case study of application-based mobile service acceptance and development in Finland. International Journal of Information Technology and Management, 9(3), 243-259. https://doi.org/10.1504/IJITM.2010.030942

Fadzil, F. (2018). A study on factors affecting the behavioral intention to use mobile apps in Malaysia. University Teknologi MARA. https://doi.org/10.2139/ssrn.3090753

Ferreira, M. B. (2016). Measuring consumer perceptions of online shopping convenience. Thesis. Catolica Porto Business School, Universidade Catolica Portuguesa.

Finmark Trust. (2015). Results from Finscope consumer survey kingdom of Cambodia 2015. Retrieved from https://finmark.org.za/results-from-finscope-consumer-survey-kingdom-of-cambodia-2015/

Ghalandari, K. (2012). The effect of performance expectancy, effort expectancy, social influence and facilitating conditions on acceptance of e-banking services in Iran: The moderating role of age and gender. Middle-East Journal of Scientific Research, 12(6), 801-807.

Google Patents. (2019). Mobile payment system. Retrieved from 
https://patents.google.com/patent/US20020073027A1/en

Grassie, K. (2007). Easy handling and security make NFC a success. Card Technology Today, 19, 12-13. https://doi.org/10.1016/S0965-2590(08)70134-8

Gupta, S. (2013). The mobile banking and payment revolution. The European Financial Review, 1-6.

Hayashi, F. (2012). Mobile payments: What's in it for consumers? Economic Review, Federal Reserve Bank of Kansas City, 35-66.

Hoffman, J., \& McVay, M. (2013). Lessons from WING Cambodia. Prepared for: Enterprise Challenge Fund. Risk Frontier Consulting.

Jambulingam, M. (2013). Behavioural intention to adopt mobile technology among tertiary students. World Applied Sciences Journal, 22(9), 1262-1271.

Javadi, M. H. M., Dolatabadi, H. R., Poursaeedi, A., \& Asadollahi, A. R. (2012). An analysis of factors affecting on online shopping behavior of consumers. International Journal of Marketing Studies, 4(5), 81-98. https://doi.org/10.5539/ijms.v4n5p81

Kadhiwal, S., \& Zulfiquar, A. U. S. (2007). Analysis of mobile payment security measures and different standards. Computer Fraud \& Security, 12-16. https://doi.org/10.1016/S1361-3723(07)70077-5

Levine, R., Loayza, N., \& Beck, T. (2000). Financial intermediation and growth: Causality and causes. Journal of Monetary Economics, 46(1), 31-77. https://doi.org/10.1016/S0304-3932(00)00017-9

Liebana-Cabanillas, F. (2012). El papel de los medios de pago en los nuevos entornos electrónicos. Tesis Doctoral. Departamento de Comercialización e Investigación de Mercados. Universidad de Granada.

Liebana-Cabanillas, F., de Luna, I. R., \& Montoro-Rios, F. (2017). Intention to use new mobile payment systems: a comparative analysis of SMS and NFC payments. Economic Research-Ekonomska Istrazivanja, 30(1), 892-910. https://doi.org/10.1080/1331677X.2017.1305784

Lorenzo, C., Alarcón, M. C., \& Gómez, M. A. (2011). Adopción de redes sociales virtuales: ampliación del modelo de aceptación tecnológica integrando confianza y riesgo percibido [Adoption of virtual social networks: Expansion of the technology acceptance model integrating trust and perceived risk]. Cuadernos de Economía y Dirección de la Empresa, 14, 194-205. https://doi.org/10.1016/j.cede.2010.12.003

Luna, I. R. (2012). Un estudio empírico de la aceptación de la tecnología NFC para pago móvil en España. Thesis. Universidad de Granada.

Morawczynski, O., \& Pickens, M. (2009). Poor people using mobile financial services: observations on customer usage and impact from M-Pesa. CGAP Brief August 2009.

Mtebe, J. S., \& Raisamo, R. (2014). Investigating students' behavioural intention to adopt and use mobile learning in higher education in East Africa. International Journal of Education and Development using Information and Communication Technology (IJEDICT), 10(3), 4-20.

Onaolapo, S., \& Oyewole, O. (2018). Performance expectancy, effort expectancy, and facilitating conditions as factors influencing smart phones use for mobile learning by postgraduate students of the University of Ibadan, Nigeria. Interdisciplinary Journal of E-Skills and Lifelong Learning, 14, 95-115. https://doi.org/10.28945/4085

Pai, F. Y., \& Huang, K. I. (2011). Applying the technology acceptance model to the introduction of healthcare information systems. Technological Forecasting and Social Change, 78, 650-660. https://doi.org/10.1016/j.techfore.2010.11.007

Pallant, J. (2013). SPSS survival manual. UK: McGraw-Hill Education.

Prime Indexes. (2018). Mobile payments: Industry overview. Retrieved from https://www.primeindexes.com/indexes/prime-mobile-payments-index/whitepaper.html

Samaradiwakara, G. D. M. N., \& Gunawardena, C. G. (2014). Comparison of existing technology acceptance theories and models to suggest a well improved theory/model. International Technical Sciences Journal (ITSJ), 1(1), 21-36.

Sarfaraz, J. (2017). Unified theory of acceptance and use of technology (UTAUT) model-mobile banking. Journal of Internet Banking and Commerce, Jahangirabad Institute of Technology.

Sarma, M. (2016). Measuring financial inclusion using multidimensional data. World Economics, 17(1), 15-40. 
Seng, K., \& Lay, S. H. (2018). Financial Inclusion: Are Mobile Phones Helpful in Cambodia? NBC Working Paper Final.

Shaw, N., \& Sergueeva, K. (2016). Convenient or Useful? Consumer Adoption of Smartphones for Mobile Commerce. DIGIT 2016 Proceedings.

Teo, A-C., Tan, G. W-H., Ooi, K-B., \& Yew, K-T. (2015). The effects of convenience and speed in m-payment. Industrial Management \& Data Systems, 115(2), 311-331. https://doi.org/10.1108/IMDS-08-2014-0231

The Statista. (2019). Global mobile payment spending from 2010 to 2017, by segment (in billion U.S. dollars). Retrieved from https://www.statista.com/statistics/244381/global-mobile-payments-market-share-forecast-by-usage/

Umphapalin, P. (2018). Factors affecting behavior intention to use quick response payment system of consumer of Bangkok. PhD. Bangkok University.

Ursachi, G., Horodnic, I. A., \& Zait, A. (215). How reliable are measurement scales? External factors with indirect influence on reliability estimators. 7th International Conference on Globalization and Higher Education in Economics and Business Administration, GEBA 2013.

Valcourt, E., Robert, J. M., \& Beaulieu, F. (2005). Investigating mobile payment: Supporting technologies, methods, and use (vol. 4, pp. 29-36). In WiMob'2005, IEEE International Conference on Wireless and Mobile Computing, Networking and Communications. https://doi.org/10.1109/WIMOB.2005.1512946

Venkatesh, V., Morris, M. G., Davis, G. B., \& Davis, F. D. (2003). User Acceptance of Information Technology: Toward a Unified View. MIS Quarterly, 27(3), 425-478. https://doi.org/10.2307/30036540

Verhoeven, J. C., Heerwegh, D., \& De Wit, K. (2011). First year university students' self-perception of ICT skills: Do learning styles matter? Education \& Information Technologies, 17(1), 109-133. https://doi.org/10.1007/s10639-010-9149-1

Yang, S., Lu, Y., Gupta, S., Cao, Y., \& Zhang, R. (2012). Mobile payment services adoption across time: An empirical study of the effects of behavioral beliefs, social influences e personal traits. Computers in Human Behavior, 28, 129-142. https://doi.org/10.1016/j.chb.2011.08.019

\section{Copyrights}

Copyright for this article is retained by the author, with first publication rights granted to the journal.

This is an open-access article distributed under the terms and conditions of the Creative Commons Attribution license (http://creativecommons.org/licenses/by/4.0/). 